\title{
DO NEDET À INCUBAÇÃO: TRAJETÓRIA DAS AÇÕES DE EXTENSÃO UNIVERSITÁRIA NO ÂMBITO DA ABORDAGEM TERRITORIAL DO DESENVOLVIMENTO ${ }^{1}$
}

\section{FROM NETED TO INCUBATION: UNIVERSITY ACTIONS IN THE TERRITORIAL DEVELOPMENT APPROACH}

\author{
José Marcos Froehlich* \\ Hector dos Santos Facco* \\ Lucas Moretz-Sohn David Vieira*** \\ Alisson Vicente Zarnott ${ }^{* * * *}$
}

\section{RESUMO:}

Este trabalho objetiva efetuar um balanço crítico da trajetória de atuação extensionista do Núcleo de Extensão em Desenvolvimento Territorial Centro Serra (NEDET CS), no período 2014-2017. Os NEDETs foram criados através da Chamada Pública CNPq/MDA/SPM-PR No 11/2014 com o objetivo de estruturar equipes de assessoramento aos Colegiados de Desenvolvimento Territorial (CODETERs). Na Universidade Federal de Santa Maria, foi constituído o NEDET CS para atuação no Território Centro Serra do Rio Grande do Sul. Entre 2014 e 2017, foram desenvolvidas atividades voltadas à gestão social e inclusão produtiva. A análise das ações realizadas aponta que o NEDET deu organicidade e promoveu a participacão social no CODETER, realizou 115 atividades e mobilizou a execução de 2,6 milhỗes de reais. Conclui-se, assim, que o NEDET teve um papel positivo na articulação e no desenvolvimento do Território CS, além de ser um espaço privilegiado de formação acadêmica através das ações de pesquisa e extensão desenvolvidas.

Palavras-chave: Extensão Universitária; Desenvolvimento Territorial; Incubação de Projetos Sociais.

\begin{abstract}
:
This study aims to provide a critical assessment on the trajectory of the extensionist activity of the Center for Extension in Territorial Development Center Serra (NEDET CS, Brazilian abbreviation), from 2014 to 2017. The NEDETs were created through the Public Call CNPq / MDA / SPM-PR No. 11/2014 in order to set up advisory teams to the Territorial Development Colleges (CODETERs, Brazilian abbreviation). At the Federal University of Santa Maria, the NEDET CS was set up to operate in the Serra do Rio Grande do Sul Center Territory. From 2014 to 2017, it was develop activities for social management and productive inclusion. The analysis of the actions point out that the NEDET has organized and promoted social participation in CODETER, carried out 115 activities and mobilized 2.6 million reais. It was concluded that the NEDET had a positive role in the articulation and development of the CS Territory besides being a privileged space for academic formation since it provides opportunity to develop research and extension actions.
\end{abstract}

Keywords: University Extension; Territorial Development; Incubation of Social Projects.

\footnotetext{
*Professor da Universidade Federal de Santa Maria (UFSM), Santa Maria - RS, Brasil. E-mail: jmarcos.froehlich@gmail.com ** Aluno de Mestrado da Universidade Federal de Santa Maria (UFSM), Santa Maria - RS, Brasil. E-mail: hectorfacco@gmail.com

${ }^{* * *}$ Aluno de Mestrado da Universidade Federal de Santa Maria (UFSM), Santa Maria - RS, Brasil. E-mail: lucasmdvieira@gmail.com **** Professor da Universidade Federal de Santa Maria (UFSM), Santa Maria - RS, Brasil. E-mail: alissonzarnott@gmail.com ***** Aluna de Graduação da Universidade Federal de Santa Maria (UFSM), Santa Maria - RS, Brasil. E-mail: hubnerjeniffer@gmail.com
} 


\section{Introdução}

Nas últimas décadas, a partir da desconstrução e relativização da noção de desenvolvimento, tornaramse importantes as emergências de ações coletivas e experiências alternativas, registrando e pensando-as junto com os que as constroem cotidianamente, na premissa de que sejam pequenos passos para a construção de diálogos mais horizontais que estabeleçam condições de possibilidade para a emergência de outras modernidades (ESCOBAR, $2005 ; \quad 2007$; MALDONADO-TORRES, 2007; CASTRO-GÓMEZ; GROSFOGUEL, 2010). Assim, a mobilização dos sujeitos envolvidos em processos de autogestão e participação social se torna estratégica para a prevalência na produção de sentidos e, portanto, para as frentes de lutas políticas e econômicas contemporâneas.

É neste contexto que emerge a abordagem territorial do desenvolvimento. Embora seja uma das formas mais recentes que assume o discurso do desenvolvimento, também pode ser considerada como a narrativa que melhores condições de diálogo e possibilidades de tensionamentos apresenta em relação a reconhecer e contemplar resistências e elaborações de propostas desde o campo dos subalternos, posto que toma como centrais as noções de identidade territorial e gestão social, através da qual múltiplos atores e agências podem intervir (CARRIERE; CAZELLA, 2006; FAVARETO, 2007).

A partir de referências em experiências europeias, vários países da América Latina passaram a discutir e implementar experiências e políticas públicas referenciadas em abordagens territoriais do desenvolvimento. Nessa perspectiva, também o governo brasileiro adotou o enfoque territorial para as políticas públicas de desenvolvimento rural no país, criando, para a sua formulação e implementação, em 2004, a Secretaria de Desenvolvimento Territorial (SDT) no âmbito do então Ministério do Desenvolvimento Agrário (MDA).

A SDT elaborou e deu início, naquele mesmo ano, ao Programa Nacional de Desenvolvimento Sustentável dos Territórios Rurais (PRONAT) (SUMPSI, 2007; CANIELLO, PIRAUX, 2015), pautado pelos objetivos de ampliar as formas de participação social, reconhecer e estimular a intersetorialidade, superar o dualismo rural versusurbano, integrar espaços, atores sociais, agentes e políticas públicas, com vistas a promover a redução da pobreza e das desigualdades, o respeito à diversidade, a solidariedade, a justiça social e, em síntese, o desenvolvimento sustentável.

$\mathrm{Na}$ trajetória desta abordagem e de suas políticas implementadas no Brasil a partir de 2004, vários formatos e desenhos institucionais foram experimentados, ocorrendo balanços críticos que paulatinamente foram incidindo, em maior ou menor grau, sobre reelaborações de diretrizes, desenhos, formatos, objetivos e relações com atores no âmbito de suas formulações e implementações (FAVARETO, 2010; GUANZIROLI, 2012; FROEHLICH，2012; SABOURIN et al., 2015).

A partir dos resultados e considerações apontados no Projeto Células (2010-2014, Edital $n^{\circ}$
005/2009 Secretaria de Desenvolvimento Territorial/ Conselho Nacional de Desenvolvimento Científico e Tecnológico / Ministério do Desenvolvimento Agrário (SDT/CNPq), foi formulada a última versão desta política territorial. Nesta reformulação, foi realizada a Chamada Pública CNPq/MDA/SPM-PR No 11/2014, voltada para as Instituições Públicas de Ensino Superior (IPES), com o intuito de implantar e consolidar, nos territórios rurais e da cidadania de todo o país, os Núcleos de Extensão em Desenvolvimento Territorial (NEDETs) como equipes de assessoramento técnico aos Colegiados de Desenvolvimento Territorial $(\text { CODETERs })^{2}$.

A referida Chamada Pública apresentava como requisito indispensável que as propostas fossem apresentadas por IPES, o que proporcionou uma inserção ímpar destas instituições no trabalho de extensão junto aos territórios rurais do país.

Através da referida Chamada, constituíram-se no país 186 NEDETs, abarcando 54 IPES, 98 professores coordenadores de projeto; 126 professores coordenadores de Núcleo; 116 bolsistas de Iniciação em Extensão; 373 bolsistas de extensão para atuar na Assessoria Territorial para Gestão Social (ATGS) e Assessoria Territorial de Inclusão Produtiva (ATIP); 92 Assessorias Territoriais de Gênero (ATG). As ações de extensão dos 186 NEDET implantados permitiram atender $78 \%$ dos territórios que compunham a política de desenvolvimento territorial, envolvendo indiretamente 2.773 municípios e uma população rural de 17,6 milhões de pessoas (BRASIL, MDA/SDT, 2016).

Foi neste âmbito que se estabeleceu o NEDET Centro Serra (NEDET CS) na Universidade Federal de Santa Maria (UFSM), com equipe de docentes, graduandos e pós-graduandos para atuação no Território Centro Serra do Rio Grande do Sul. Com a abrupta mudança política ocorrida no Brasil em 2016, acarretando a extinção da SDT e do MDA, cessou todo o apoio federal à política territorial e houve a descontinuidade da grande maioria dos NEDETs implantados no país. Para não ser extinto, o NEDET CS buscou novas estratégias no âmbito institucional e no foco de sua atuação.

Em termos gerais, reveste-se de grande importância a avaliação da eficácia das políticas públicas, articuladas na abordagem territorial do desenvolvimento, em sua capacidade de promover a melhoria das condições de vida dos segmentos da população mais vulneráveis socioeconomicamente, uma vez que o Território Centro Serra do RS apresenta o pior Índice de Desenvolvimento Humano (IDH) entre os territórios rurais gaúchos. Em termos mais específicos, também é relevante a reflexão sobre as ações extensionistas realizadas, para que eventuais problemas e limitações possam ser mais bem compreendidos, dimensionados e, quiçá, superados.

Assim, este trabalho objetiva efetuar um balanço crítico da trajetória de atuação extensionista do NEDET CS no período 2014-2017, buscando analisar os resultados para o público envolvido. 


\section{Método}

O Território Centro Serra (Figura 1) constituiuse formalmente no ano de 2006, por intermédio da solicitação dos gestores públicos da região que compõem a Associação dos Municípios do Centro Serra (AMCSERRA). Segundo a congregação territorial estipulada pelo extinto MDA, o Território Centro Serra é composto por Arroio do Tigre, Cerro Branco, Estrela Velha, Ibarama, Jacuizinho, Lagoa Bonita do Sul, Lagoão, Passa Sete, Salto do Jacuí, Segredo, Sobradinho e Tunas, com uma área total de $3.190 \mathrm{~km}^{2}$ e uma população total de 79.325 habitantes, dos quais 41.976 residem em áreas rurais (BRASIL, MDA/SDT, 2009).

Todos os municípios do território são constituídos de pequenas populações, sendo que o município mais populoso é Sobradinho, com cerca de 14 mil habitantes. Com exceção dos municípios de Arroio do Tigre e Sobradinho, os demais municípios possuem população rural superior à população urbana.

Figura 1 - Mapa do Território Centro Serra do Rio Grande do Sul.

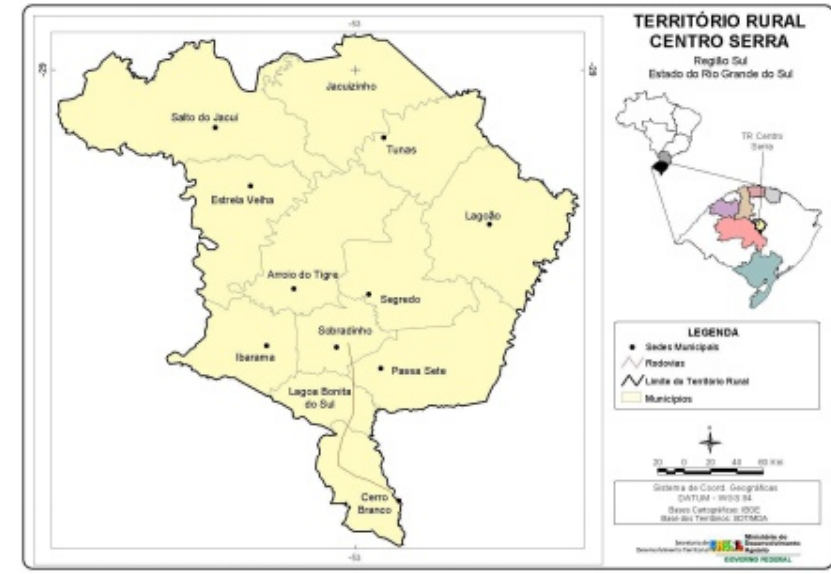

Fonte: (BRASIL, MDA/SDT, 2009).

Segundo dados do Censo Agropecuário de 2006 (BRASIL, MDA/SDT, 2009), o território Centro Serra tem $93 \%$ de seus estabelecimentos agropecuários enquadrados na categoria agricultura familiar e, cabe destacar, com uma grande diversidade socioeconômica e etnocultural oriunda dos diversos grupos que compõem a agricultura familiar do território, dentre os quais cabe destacar as famílias de origem étnica italiana e alemã descendentes dos imigrantes que ocuparam a região no período da colonização (1875), famílias que chegaram à região através da constituição de assentamentos de reforma agrária (206 famílias em 5 assentamentos), 71 famílias quilombolas (oriundas de três comunidades) e 117 famílias indígenas, também distribuídas em três comunidades localizadas no território (BRASIL, MDA/SDT, 2009).

A estratégia metodológica utilizada pelo NEDET buscou combinar dois instrumentais da ação extensionista: as metodologias participativas e o mapeamento de redes territoriais temáticas, derivado da abordagem do mapeamento das redes sociais (ASSIS, 2001; GEILFUS, 2002; TOMMASINO et al., 2006). A primeira dedicada a fortalecer as experiências de gestão social participativa através do uso de ferramentas e técnicas participativas de mediação; e a segunda, focada na construção e no fortalecimento de redes sociais responsáveis por criar planos executivos de desenvolvimento territorial que deram forma ao Banco de Projetos Territoriais, cujo intuito visava fortalecer a inclusão produtiva e a geração de trabalho e renda.

O mapeamento das redes sociais permitiu visualizar concretamente os laços de relacionamentos sociais em dados intervalos temporais, facilitando a compreensão dessas relações (CALGARO NETO; DIESEL, 2009) e, deste modo, tornou-se um excelente meio para compreender as dinâmicas relacionadas aos processos de construção de matrizes ou estruturas de gestão social, colaborando para a observação das mudanças derivadas direta ou indiretamente das mediações sociais no território. Em termos operacionais, as redes territoriais temáticas concentraram esforços de automobilização, avançando-se gradativamente para a construção de planejamentos participativos, cujo objetivo principal era a alimentação qualificada do Banco de Projetos Territoriais do CODETER CS. Este, por sua vez, tornou-se o plano executivo para os diversos eixos temáticos que passaram a constar no PTDRS do referido CODETER.

Neste processo, a assessoria técnica do NEDET CS promoveu dinâmicas de mobilização e participação social, de modo a manter ativas as diversas redes em seus objetivos de planejar e executar ações de desenvolvimento territorial. Necessitou-se, para tal, de contínuos processos de animação dos atores sociais em prol da construção de diagnósticos, planejamentos, cronogramas de trabalho, avaliação e monitoramento. A Figura 2 apresenta uma imagem ilustrativa da dinâmica das redes territoriais temáticas em contexto de promoção do desenvolvimento territorial através do CODETER CS.

Figura 2 - Imagem ilustrativa da dinâmica das redes territoriais temáticas no território Centro Serra do RS

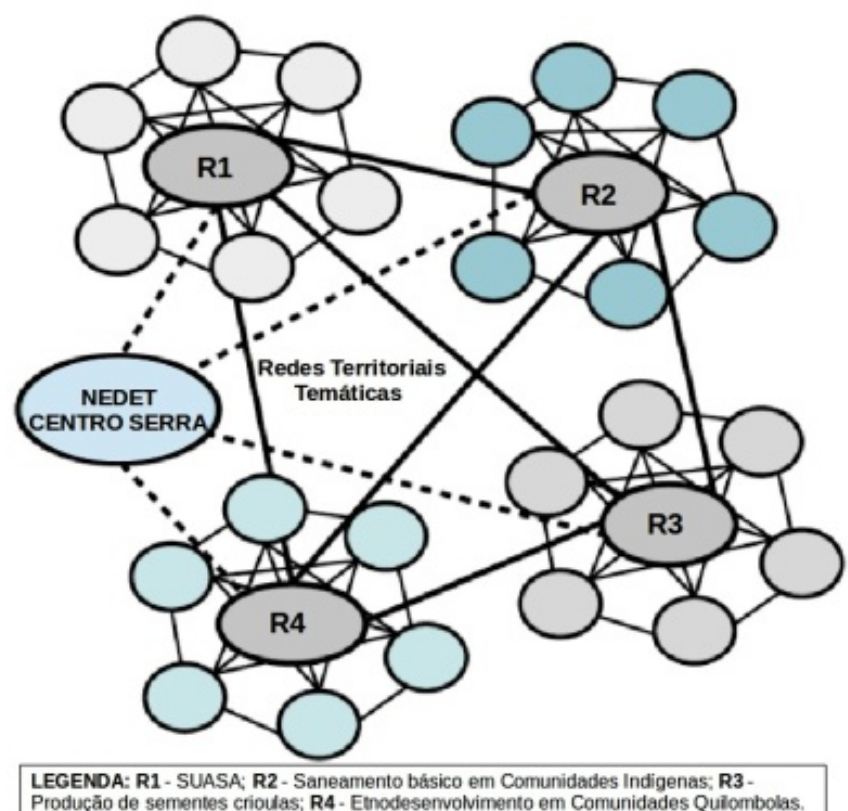

Produç̃̃ : R1 - SUASA; R2 - Saneamento básico em Comunidades indigenas, R3 -

Fonte: Autores

As ferramentas de Diagnóstico Rural Participativo (DRP), por sua vez, disponibilizaram um conjunto de instrumentos para a realização de atividades relacionadas à formação de grupos, diagnósticos rurais, análise de problemas e planejamentos participativos (GEILFUS, 2002). Deste 
modo, a utilização das mesmas se adequou à busca por dinamizar as redes territoriais para a construção de distintos projetos temáticos no Território Centro Serra do RS. Não obstante, foi necessária a capacitação afinada da equipe de trabalho do NEDET CS para que a utilização das ferramentas citadas atingisse seus objetivos.

\section{A atuação do NEDET Centro Serra sob a política territorial da SDT-MDA}

A Chamada Pública CNPq/MDA/SPM-PR No 11/2014, que implantou e consolidou os NEDETs nos territórios rurais do país, colocou como responsabilidade para os mesmos a produção de dados, informações e pesquisas; a geração e troca de conhecimentos, métodos e tecnologias sociais e o monitoramento, avaliação e prestação de assessoria técnica aos CODETERs. Sua ação devia envolver os diversos aspectos dos processos de gestão social e de efetivação de políticas públicas de desenvolvimento rural e de inclusão produtiva nos Territórios Rurais.

Com a aprovação do projeto do NEDET CS, montou-se uma estrutura de trabalho que contratou profissionais que tinham dedicação exclusiva para as ações do projeto. A equipe foi formada por 3 profissionais graduados (2 com mestrado e 1 com doutorado), sendo: 1 Assessor Territorial de Gestão Social (ATGS), 1 Assessor Territorial de Inclusão Produtiva (ATIP) e 1 Assessor Territorial de Gênero (ATG). O projeto contava com rubrica para aquisição de material permanente para equipar uma sede de trabalho, bem como rubrica para custeio que abarcava aluguel de veículos, combustível e diárias. Este conjunto de recursos (humanos, financeiros e estruturais) foi fundamental para a execução das ações de extensão, devido à necessidade de deslocamento dos profissionais para atuação no território, distante cerca de $120 \mathrm{Km}$ da UFSM.

As ações de extensão efetuadas pelo NEDET CS podem ser agrupadas em 3 modalidades, quais sejam:

Gestão social -> conjunto de ações que priorizaram a mobilização e a participação social dos atores do território, adotando como estratégia o uso de ferramentas ligadas à abordagem participativa. Compõe essa modalidade as mediações das sessões das Plenárias Territoriais, das reuniões do Núcleo técnico e Dirigente (NDT) e das reuniões dos comitês territoriais.

Inclusão produtiva -> conjunto de ações com o caráter de diagnóstico, planejamento e formulação de ações e/ou projetos para a geração de trabalho e renda, juntamente aos diversos atores do território. Para exemplificar este grupo de ações, tem-se as visitas técnicas às associações, as visitas às instituições parceiras na execução de projetos (Escritórios Municipais da Emater - RS, as prefeituras municipais e o Consórcio Intermunicipal do Vale do Jacuí) e, ainda, ações com o caráter de monitoramento dos recursos já implementados no território.

Outros -> conjunto de ações com motivações diferentes dos propósitos anteriores, como aquelas ligadas à capacitação e planejamento da equipe técnica do NEDET CS, sejam estas internas ou realizadas juntamente a outras equipes de NEDET's ou da SDT/MDA. Cita-se, ainda, a participação em eventos que dialogavam com a abordagem de desenvolvimento territorial.

No Quadro 1, podemos visualizar a envergadura que alcançou o projeto de implantação e consolidação do NEDET CS sob os auspícios da política territorial da então SDT-MDA.

Quadro 1 - Modalidades de ações de extensão desenvolvidas entre 2014 e 2016 pelo NEDET - Centro Serra do Rio Grande do Sul.

\begin{tabular}{|c|c|c|c|c|c|}
\hline Ano & $\begin{array}{c}\text { Categoria } \\
\text { da ação }\end{array}$ & $\begin{array}{l}\text { Número } \\
\text { de ações }\end{array}$ & Beneficiários & Descrição & TOTAL \\
\hline 2014 & Outros & 1 & Equipe técnica & $\begin{array}{l}\text { Planejamento da Equipe Técnica } \\
\text { (Coordenador, ATGS, ATIP, } \\
\text { Bolsista, Pesquisadores) }\end{array}$ & 1 \\
\hline \multirow{3}{*}{2015} & $\begin{array}{l}\text { Gestão } \\
\text { social }\end{array}$ & 18 & $\begin{array}{l}\text { Todos os sujeitos } \\
\text { do temritório }\end{array}$ & $\begin{array}{c}\text { Foram considerados neste tópico } \\
\text { todas as atividades de mobilização, } \\
\text { apresentação e articulaçǒes ligadas } \\
\text { diretamente ao funcionamento do } \\
\text { CODETER, além dos encontros } \\
\text { referentes às suas instâncias de } \\
\text { gestão colegiada. }\end{array}$ & \multirow{3}{*}{45} \\
\hline & $\begin{array}{l}\text { Inclusào } \\
\text { produtiva }\end{array}$ & 18 & $\begin{array}{l}\text { Todos os sujeitos } \\
\text { do território }\end{array}$ & $\begin{array}{l}\text { Atividades vinculadas à construção, } \\
\text { elaboração, implementação, } \\
\text { execução e monitoramento de } \\
\text { projetos de interesse dos públicos } \\
\text { beneficiários da politica territorial. }\end{array}$ & \\
\hline & Outros & 9 & $\begin{array}{l}\text { Equipe técnica }+ \\
\text { Públicos do } \\
\text { território }\end{array}$ & $\begin{array}{c}\text { Atividades vinculadas a reuniões, } \\
\text { capacitações estaduais ou nacionais } \\
\text { e planejamento dos membros das } \\
\text { equipes que atuam no } \\
\text { desenvolvimento territorial, bem } \\
\text { como eventos de caráter } \\
\text { Representativo (conferências de } \\
\text { ATER). }\end{array}$ & \\
\hline \multirow{3}{*}{2016} & $\begin{array}{l}\text { Gestão } \\
\text { social }\end{array}$ & 28 & $\begin{array}{l}\text { Todos os sujeitos } \\
\text { do território }\end{array}$ & $\begin{array}{l}\text { Foram considerados neste tópico } \\
\text { todas as atividades de mobilização, } \\
\text { apresentação e articulações ligadas } \\
\text { diretamente ao funcionamento do } \\
\text { CODETER, além dos encontros } \\
\text { referente às suas instâncias de } \\
\text { gestão colegiada. }\end{array}$ & \multirow{3}{*}{70} \\
\hline & $\begin{array}{l}\text { Inclusão } \\
\text { produtiva }\end{array}$ & 25 & $\begin{array}{l}\text { Todos os sujeitos } \\
\text { do território }\end{array}$ & $\begin{array}{c}\text { Atividades vinculadas à } \\
\text { construção, elaboração, } \\
\text { implementaçâa, execução e } \\
\text { monitoramento de projetos de } \\
\text { interesse dos públicos beneficiários } \\
\text { da política territorial. }\end{array}$ & \\
\hline & Outros & 17 & $\begin{array}{l}\text { Equipe técnica }+ \\
\text { Públicos do } \\
\text { território }\end{array}$ & $\begin{array}{c}\text { Atividades vinculadas a reuniões, } \\
\text { capacitações estaduais ou nacionais } \\
\text { e planejamento dos membros das } \\
\text { equipes que atuam no } \\
\text { desenvolvimento territorial, bem } \\
\text { como eventos de caráter } \\
\text { Representativo (conferências de } \\
\text { ATER). }\end{array}$ & \\
\hline \multicolumn{5}{|c|}{ TOTAL } & 116 \\
\hline
\end{tabular}

Fonte: Autores.

No ano de 2015, que foi o de efetiva implantação do NEDET CS, realizou-se um total de 45 ações, que passam pelas 3 modalidades, sendo 18 ações de gestão social, 18 de Inclusão produtiva e 9 de outras aç̃es. As ações de gestão social estavam ligadas à mobilização dos atores territoriais e à construção de uma "rotina" para as atividades ligadas às instâncias do CODETER CS. As ações ligadas à Inclusão Produtiva tinham o caráter de busca de informaçoes sobre os recursos já acessados pelos editais do Programa de Apoio à Infraestrutura nos Territórios Rurais (PROINF) anteriores e visitas técnicas para diagnosticar as necessidades e demandas dos atores. Já as "outras" ações foram realizadas conforme a necessidade de planejamento da equipe, bem como a participação em atividades propostas por outros órgãos, como a SDT/MDA.

Referente ao ano de 2016, em que já estava estabelecida uma dinâmica de atividades para o 
CODETER CS, e com uma razoável compreensão da realidade encontrada no território por parte da equipe do NEDET CS, ocorreu uma intensificação dos trabalhos em todas as modalidades, como é apresentado no Quadro 1, totalizando 70 ações de extensão. Isso se desenvolveu de uma forma articulada, de modo que tanto as ações de gestão social como as de inclusão produtiva estabeleciam conexões recíprocas, como no caso da redistribuição dos equipamentos referentes a algumas metas do projeto do PROINF de 2010. Por fim, as atividades chamadas de "outras" também aumentaram a sua demanda, visto o planejamento, capacitação da equipe e a participação em eventos com a temática territorial.

Além disso, houve a busca de informações e resgate referente à execução dos recursos atrasados do PROINF desde 2010 até 2014, ano de início da vigência da chamada pública dos NEDET's, totalizando 12 projetos de custeio e de investimentos em infraestrutura no território, e ainda estavam em trâmite, em 2016, os projetos dos editais do PROINF de 2015 e 2016. O montante mobilizado em recursos via projetos foi de $\mathrm{R} \$ 2.671 .758,05$, no intervalo de 2010 a 2016, referentes à política territorial.

$\mathrm{O}$ número total de aç̃es desenvolvidas nos 2 anos de vigência da chamada pública perfaz um total de 116 ações de diversas naturezas, como podemos ver na Figura 3.

Figura 3 - Ações realizadas pelo NEDET Centro Serra, 2015-2016.

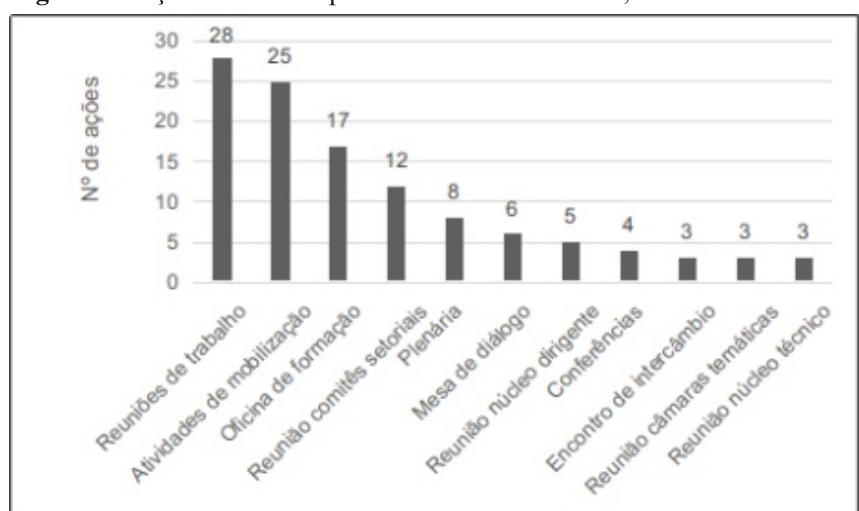

Fonte: Autores.

No final do ano de 2016, houve o encerramento da chamada pública e a sua não renovação. Diante disso, havia uma importante decisão a tomar: dissolver o Núcleo ou tentar alternativas para a sua continuidade. A opção foi por tentar manter o NEDET $\mathrm{CS}$, em razão dos compromissos assumidos junto aos atores do território, o entendimento dos membros do colegiado sobre a importância do trabalho desempenhado, bem como pelo espaço de formação dos recursos humanos que uma experiência de extensão universitária como aquela vinha e poderia continuar proporcionando.

\section{O fim da política territorial e a atuação do NEDET Centro Serra}

A extinção do MDA, em 2016, juntamente com o encerramento da chamada pública que formou os
NEDET's, afetou enormemente os processos que estavam sendo desenvolvidos a partir da abordagem territorial no país.

Considerando a ativa articulação do Território, o compromisso do NEDET CS com o desenvolvimento do mesmo e com os atores envolvidos, o NEDET CS buscou trabalhar alternativas para manutenção da assessoria ao CODETER CS. Estas estratégias passaram a criar articulações com atores territoriais, como o Consórcio Intermunicipal do Vale do Jacuí (CI-JACUÍ) e prefeituras municipais, porém, nenhuma destas estratégias deu resultados satisfatórios. O caminho posterior foi buscar suporte em editais internos da UFSM voltados à extensão universitária, especialmente do Fundo de Incentivo à Extensão (FIEX). Formulou-se o Programa de Extensão em Desenvolvimento Territorial do Território Centro Serra (PREDETER CS) e se submeteu proposta ao edital FIEX 2017, a fim de tentar manter algumas ações do NEDET no território Centro Serra. O Programa foi contemplado, recebendo duas bolsas de iniciação à extensão (IEX) para estudantes de graduação por oito meses e cerca de 6 mil reais para verba de custeio e almoxarifado da universidade.

A contemplação pelo edital FIEX tornou minimamente possíveis algumas atividades no território, mas mudou o caráter da assessoria prestada ao CODETER CS. O principal motivo da mudança foi o aporte de recursos significativamente menor disponibilizado pelo FIEX, em comparação ao da chamada pública CNPq-MDA-SDT 2014, não havendo mais como manter uma equipe com profissionais graduados em atividade com dedicação exclusiva. A consequência dessas novas condições foi uma diminuição notável das ações desempenhadas pelo NEDET CS no território. As ações desenvolvidas através do PREDETER, no ano de 2017, encontram-se quantificadas na Figura 4.

Figura 4 - Resumo das ações realizadas pelo NEDET Centro Serra mediante o PREDETER Centro Serra no ano de 2017.

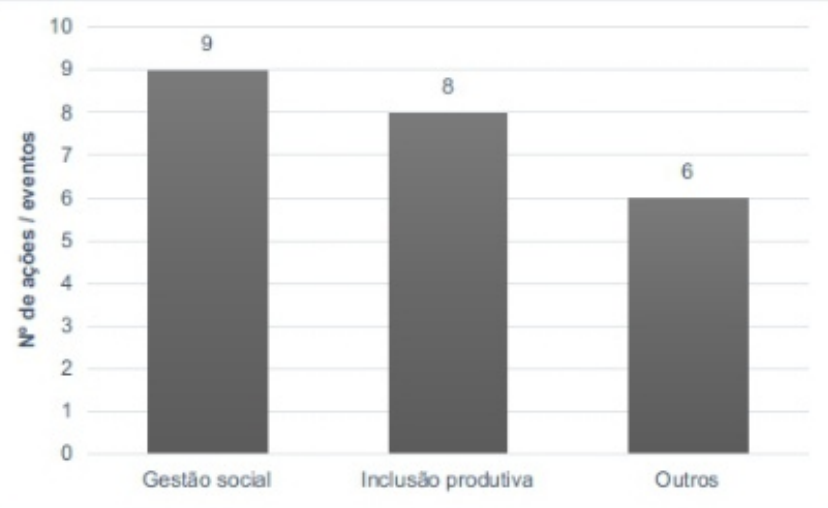

Fonte: Autores.

Em 2017, foram realizadas 9 ações de gestão social, sendo elas: Plenárias Territoriais, Reuniões dos Comitês Territoriais e Reuniões dos Núcleos Técnico e Dirigentes. A diminuição significativa em relação aos anos anteriores deve-se à falta de investimento para uma assessoria adequada para a promoção do desenvolvimento territorial e o desmonte da política territorial. A categoria "outros" refere-se às atividades internas como reuniões, capacitações e planejamentos da equipe técnica, assim como as participações em eventos sobre temáticas circundantes. As ações de 
inclusão produtiva constituíram-se da busca de recurso através de editais e a elaboração de projetos que contemplassem as demandas levantadas pelo Núcleo Técnico Dirigente do CODETER CS. Os principais editais monitorados via websites foram os da plataforma do governo federal, os PROINFs, os do CNPq, os FIEX e os da UFSM. Destacam-se, no Quadro 2, os seguintes projetos elaborados através do PREDETER CS em 2017.

Quadro 2 - Banco de projetos implementados através do PREDETER Quadro 2 - Banco

\begin{tabular}{|c|c|}
\hline Rede temática & Objetivo \\
\hline Saneamento Básico & Plano Territorial de Saneamento Básico no Território Centro Serra \\
\hline SUASA & Adesão ao Sistema Unificado de Atenção à Sanidade Agropecuária \\
\hline Mulheres & $\begin{array}{l}\text { Programa de Apoio à Infraestrutura nos Territórios Rurais para o } \\
\text { fortalecimento de dois grupos organizados de mulheres rurais }\end{array}$ \\
\hline $\begin{array}{l}\text { Comunidades } \\
\text { Indígenas }\end{array}$ & $\begin{array}{l}\text { Banco de sementes crioulas para a comunidade indígena Kaingang de Júlio } \\
\text { Borges }\end{array}$ \\
\hline \multirow{3}{*}{$\begin{array}{l}\text { Comunidades } \\
\text { Quilombolas }\end{array}$} & $\begin{array}{l}\text { Programa de Apoio à Infraestrutura nos Territórios Rurais para a Comunidade } \\
\text { Remanescente de Quilombo de Júlio Borges }\end{array}$ \\
\hline & $\begin{array}{l}\text { Dois projetos para dois comunidades quilombolas objetivando o } \\
\text { desenvolvimento, a fim de superar o estado de vulnerabilidade social, através } \\
\text { da inclusão produtiva e geração de renda via Incubadora Social da UFSM }\end{array}$ \\
\hline & $\begin{array}{l}\text { Incubação de projetos sociais e o desenvolvimento territorial das mesmas duas } \\
\text { comunidades quilombolas para geração de renda com vistas à superação do } \\
\text { estado de vulnerabilidade social via edital CNPq }\end{array}$ \\
\hline
\end{tabular}

A mudança de recursos disponíveis para a prática da assessoria do NEDET CS ao CODETER CS e a extinção das políticas públicas financiadoras de projetos sociais nos territórios levaram o núcleo a restringir a sua atuação no território. Foram possíveis menos idas até os municípios, menos Plenárias Territoriais, menos capacitações internas e territoriais e menos editais e recursos públicos. Essas limitações levaram o NEDET CS a focar as suas ações nos públicos prioritários da política territorial, priorizando projetos vinculados às comunidades quilombolas.

Dentre as demandas dos públicos prioritários do CODETER CS, os projetos de geração de renda e inclusão produtiva das comunidades quilombolas Júlio Borges (Salto do Jacuí, RS) e Linha Fão (Arroio do Tigre, RS) foram contemplados em dois editais em 2017: Incubadora Social da UFSM e CNPq. Estes dois editais foram a fonte de recursos para os meses finais de 2017 e para a manutenção da atuação em 2018.

\section{O NEDET Centro Serra e a incubação social}

No início de 2017, a Incubadora Social (IS) da UFSM abriu inscrição para incubação de coletivos em situação de vulnerabilidade social e em processo de organização solidária, visando à geração de trabalho e renda com viés da sustentabilidade socioambiental. A oportunidade contemplou duas propostas de incubação baseadas em infraestruturas adquiridas através de editais PROINFs e na participação das comunidades quilombolas no CODETER CS, sendo uma proposta da Comunidade Quilombola Linha Fão e outra da Associação Comunitária Remanescentes de Quilombo Júlio Borges.

A IS prevê recurso de custeio e empréstimo de material permanente, alguns deslocamentos da comunidade e da IS e NEDET até as comunidades e aquisição de alguns materiais permanentes via licitação na universidade. Poucas ações foram realizadas até o momento, pois o processo formal do contrato de incubação está em fase inicial (fase denominada de pré-incubação), além de que a extensão universitária é limitada pelos excessos burocráticos e corporativos.

Todavia, a incubação desses dois projetos permitiu a concorrência no edital $\mathrm{n}^{\circ}$ 27/2017 do CNPq/MTb-SENAES Apoio a Empreendimentos Econômicos Solidários, que visava estimular o aprimoramento destes empreendimentos já incubados articulados a processos de desenvolvimento territorial. Selecionado neste edital, o projeto submetido prevê custeio de material de consumo e material permanente, 2 bolsas EXP-B (para graduados) e 1 bolsa IEX para graduando, combustível e diárias, recursos que contribuirão para a manutenção e qualificação da ação do NEDET junto às comunidades quilombolas do Território CS.

\section{Considerações Finais}

A política territorial vem contribuir com um papel fundamental na sociedade no quesito de democratização das políticas públicas, transferindo a responsabilidade dos gestores tradicionais às instâncias de gestão colegiada, com um processo de gestão mais participativo que pode contemplar necessidades que antes não ecoavam até os gabinetes dos representantes políticos. Dentro deste cenário e na busca do aperfeiçoamento na execução da política de desenvolvimento territorial, gerou-se a maior experiência de extensão universitária em abrangência no país, e esta contribuiu de modo a qualificar os processos de mediação e execução dos Planos territoriais, como foi o caso retratado no Território Centro Serra.

Com a mudança do cenário político no país e a drástica opção por não dar sequência à abordagem territorial e às ações dos NEDET's, ocorreu um cenário de desmonte das ações, articulações, planejamentos e de uma abordagem de controle social e mais democrática para a tomada de decisões sobre os investimentos públicos. Consequentemente, também se estagnou a aproximação mais sistemática das universidades às realidades dos diversos territórios rurais no país.

No caso do NEDET Centro Serra, optou-se por continuar com as atividades, em contraponto ao destino de dissolução da grande maioria dos NEDETs do país. A continuidade foi possível graças a um esforço coletivo da equipe do NEDET e dos atores do território que, mesmo sob forte restrição de recursos, decidiram por priorizar atividades em favor de comunidades socialmente mais vulneráveis. Esta persistência permitiu que propostas de duas comunidades quilombolas pudessem ser acolhidas para incubação na IS-UFSM, e mais recentemente pudessem ter proposta contemplada em edital do CNPq.

Por fim, avalia-se que o NEDET Centro Serra vem sendo um espaço que tem desempenhado um papel importante na formação de recursos humanos, produção de conhecimentos e extensionismo para atuar 
em consonância com a abordagem territorial do desenvolvimento, ainda pouco exercitada e conhecida, mas fundamental para a articulação e eficácia das políticas públicas pautadas pela gestão social participativa, inclusão social e geração de trabalho e renda para os mais pobres.

\section{Notas:}

1 Este trabalho contou com auxílio do CNPq, CAPES e FIEXUFSM.

2 CODETER é a instância de participação social (com presença do poder público e da sociedade civil) a quem se atribuía o papel de propor e formular propostas de desenvolvimento para o seu respectivo território através de Planos Territoriais de Desenvolvimento Rural Sustentável (PTDRS) (CANIELLO, PIRAUX, 2015; BRASIL, MDA/SDT, 2016). Os PDTRS, por sua vez, deviam ter 2 eixos de atuação: a gestão social, que se refere a processos de democracia participativa e empoderamento dos atores da sociedade civil; e a inclusão produtiva, voltada a elaboração de projetos que melhorassem as condições de geração de trabalho e renda para públicos prioritários: assentados da reforma agrária, indígenas, quilombolas, agricultores familiares, jovens e mulheres (BRASIL, MDA/SDT, 2005).

\section{Referências}

ASSIS, W. S. Redes sociais para o processo de inovação em comunidades rurais. In: SIMÕES, A. et al. (Org.) Agricultura familiar: métodos e experiências de pesquisadesenvolvimento. Belém: NEAF, 2001. p. 23-54.

BRASIL. Ministério do Desenvolvimento Agrário (MDA). Secretaria de Desenvolvimento Territorial (SDT). Plano Territorial de Desenvolvimento Rural Sustentável: guia para o planejamento. Brasília: MDA/SDT, 2005. 63 p. Disponível em:

$<$ http://sge.mda.gov.br/bibli/documentos/tree/doc 220-28-

11-2012-12-04-356539.pdf $>$. Acesso em: 22 set. 2016.

\section{Plano territorial de} desenvolvimento rural sustentável do Território Centro Serra. Brasília: SDT/MDA, 2009. 73 p. Disponível em: $<$ www.sit.mda.gov.br/download/ptdrs/ptdrs_qua_territorio1 48.pdf>. Acesso em: 21 jun. 2016.

\section{Perfil Territorial Centro}

Serra. Brasília: CGMA, 2015. Disponível em: $<$ www.sit.mda.gov.br/download/caderno/caderno_territorial 148 Centro\%20Serra\%20-\%20RS.pdf $>$. Acesso em: 21 jun. $\overline{2016 .}$

\section{Balanço de gestão:}

Resultados das ações da SDT 2015-2016. Brasília: MDA/SDT, 2016. 89 p.

CALGARO NETO, S.; DIESEL, V. Redes Sociais e Constituição de Referentes Técnicos em Cooperativa de Piscicultores em Santa Maria, RS. In: CONGRESSO DA SOBER, 47., 2009, Porto Alegre/RS. Anais.... Porto Alegre/RS: Universidade Federal do Rio Grande do Sul, 2009. 18 p.

CANIELLO, M.; PIRAUX, M. Avanços, dilemas e perspectivas da governança territorial no Brasil: reflexões sobre o Programa de Desenvolvimento Sustentável de Territórios Rurais (PRONAT). Anales del Congreso Internacional Gestión Territorial Para el Desarrollo Rural. (Red GTD). Bogotá, 2015. 102 p.
CARRIÈRE, J. P.; CAZELLA, A. A. Abordagem introdutória ao conceito de desenvolvimento territorial. Eisforia, Florianópolis, v. 4, n. especial, p. 23-48, dez., 2006.

CASTRO-GÓMEZ, S.; GROSFOGUEL, R. (Comp.). El giro decolonial: reflexiones para una diversidad epistémica más allá del capitalismo global. Bogotá: Siglo del Hombre Editores; Pontificia Universidad Javeriana, Instituto Pensar, 2010. 133 p.

ESCOBAR, A. El "postdesarrollo" como concepto y práctica social. In: MATO, D. (Org.). Políticas de economía, ambiente y sociedad en tiempos de globalización. Caracas: Universidad Central de Venezuela, 2005. p. 17-31.

La invención del Tercer Mundo: construcción y deconstrucción del desarrollo. Bogotá: Editorial Norma, 2007.

FAVARETO, A. A. Paradigmas do desenvolvimento rural em questão. São Paulo: Iglu/Fapesp, 2007. p.220.

Abordagem territorial do desenvolvimento rural mudança institucional ou "inovação por adição"? Estudos Avançados, São Paulo, v. 24, n. 68, 2010. p. 299-319.

FROEHLICH, J. M. (Org.). Desenvolvimento territorial: produção, identidade e consumo. Ijuí: Ed.Unijuí, 2012. p.288.

GEILFUS, F. 80 herramientas para el desarrollo participativo: diagnóstico, planificación, monitoreo, evaluación. San José, C.R.: IICA, 2002. p.29-64.

GUANZIROLLI, C. Desenvolvimento territorial rural no Brasil - uma polêmica. In: FROEHLICH, J. M. (Org.). Desenvolvimento Territorial: Produção, identidade e Consumo. Ijuí: Ed. Unijuí, 2012. p.203-224.

MALDONADO-TORRES, N. Sobre la colonialidad del ser: contribuciones al desarrollo de un concepto. In: CASTROGÓMEZ, S.; GROSFOGUEL, R. (Comp.). El Giro Decolonial. Reflexiones para uma diversidade epistémica mas allá del capitalismo global. Bogotá, Siglo del Hombre Editroes, Universidad Central, Instituto de Estudios Sociales Contemporáneos y Pontifica Universidad Javerias, Instituto Pensar, 2007, p. 127-168.

SABOURIN, E.; MASSARDIER, G.; SOTOMAYOR, O. As políticas de desenvolvimento territorial rural na América latina: uma hibridação das fontes e da implementação. Mundos Plurales, Quito, Ecuador, v.3, n. 1, p. 75-98, 2015.

SUMPSI, J.M. Desarrollo rural com enfoque territorial: diferencias e semejanzas de las experiências de la Unión Europea y América Latina. In: ORTEGA, A.C.; ALMEIDA FILHO, N. (Orgs.). Desenvolvimento territorial, segurança alimentar e economia solidária. Campinas: Alínea, 2007. p. 30-86.

TOMMASINO, H.; FABREAU, M.; GUEDES E. Mapeo de los actores sociales: una metodología de visualización relacional y posicional. Introducción a un enfoque reticular en el marco del desarrollo local. In: TOMMASINO, H.; HEGEDUS, P. Extensión: reflexiones para la intervención en el medio rural. Montevideo: Universidad de la República - Facultad de Agronomía, 2006. p. 231-244. 